\title{
Involvement of MM cell-derived exosomes in T lymphocytes immune responses
}

\author{
QING SHAO*, LING DENG* , HUI LIU, ZHAOYUN LIU, JIN CHEN, \\ FENGJUAN JIANG, SIYANG YAN and RONG FU
}

Department of Hematology, Tianjin Medical University General Hospital, Heping, Tianjin 300052, P.R. China

Received May 12, 2019; Accepted April 30, 2020

DOI: $10.3892 / \mathrm{ol} .2020 .11892$

\begin{abstract}
Exosomes were reported to mediate cell communication in the tumor microenvironment; however, the effects of multiple myeloma (MM)-derived exosomes on the quantity and function of $\mathrm{T}$ cells remain unknown. Exosomes were extracted from MM cell lines (OPM2 and U266B1) by ultracentrifugation using a Total Exosome Isolation kit. Exosomes were co-cultured with CD4+ T, CD8+ T and regulatory $\mathrm{T}$ (Treg) cells that were isolated from healthy donors (HDs) and patients with MM using magnetic beads. Flow cytometry was used to detect $\mathrm{T}$ cells apoptosis and expression of perforin and granzyme B in CD8+ T cells. Cell viability was detected using Cell Counting kit-8, and interleukin 10 (IL-10) and transforming growth factor $\beta$ (TGF- $\beta$ ) in cell supernatants were detected by ELISA. The apoptosis of HD-CD4+ T was higher in the OPM2 group, and viability in the U266B1 group was decreased. The apoptosis of HD-CD8+ T decreased in the OPM2 and U266B1 groups, and cell viability increased in the OPM2 and the U266B1 groups. Perforin of HD-CD8+ T in the $\mathrm{U} 266 \mathrm{~B} 1$ group was lower while perforin of $\mathrm{MM}-\mathrm{CD} 8+\mathrm{T}$ in OPM2 and U266B1 groups was markedly decreased. The apoptosis of HD-Treg was lower in the U266B1 group, but apoptosis of MM-Treg was higher in the U266B1 group. The viability of HD-Treg in U266B1 group increased but the viability of MM-Treg in OPM2 and U266B1 groups decreased. TGF- $\beta$ from MM-Treg decreased in the OPM2 and U266B1 groups
\end{abstract}

Correspondence to: Professor Rong Fu, Department of Hematology, Tianjin Medical University General Hospital, 154 Anshan Street, Heping, Tianjin 300052, P.R. China

E-mail: florai@sina.com

*Contributed equally

Abbreviations: MM, multiple myeloma; HD, healthy donor; Treg, regulatory $\mathrm{T}$ cell; DC, dendritic cell; PBMCs, peripheral blood mononuclear cells; MHC, major histocompatibility complex; TEX, tumor-derived exosome; GrB, granzyme B; DEX, dendritic cell-derived exosome; IL, interleukin; TGF- $\beta$, transforming growth factor $\beta$; HSP 70, heat shot protein 70; EV, extracellular vesicle

Key words: exosomes, T lymphocyte, immunity, multiple myeloma when compared with the control group $(\mathrm{P}<0.05)$. MM-derived exosomes promote apoptosis and inhibit proliferation of HD-CD4+ T, inhibit apoptosis and promote proliferation, but inhibit perforin of HD-CD8+ T, inhibit apoptosis and promote proliferation HD-Treg, and inhibit perforin of MM-CD8+ T and TGF- $\beta$ secretion of MM-Treg.

\section{Introduction}

Multiple myeloma (MM) is a neoplastic plasma cell disorder characterized by clonal proliferation of malignant plasma cells in the bone marrow, and usually by the presence of monoclonal protein in the blood and/or urine of patients. MM is associated with end-organ damage consisting of anemia, renal insufficiency, bone lesions and/or hypercalcemia (1). $\mathrm{MM}$ is the second most frequent hematological disease. The incidence rate of MM in Europe was 3.8 in every 100,000 individuals in 2012, and the mortality rate was 2.2 (2). With the application of new drugs, including proteasome inhibitor, immunomodulatory agent and anti-CD38 monoclonal antibody, the curative efficacy in patients with MM has been significantly improved. The median overall survival (OS) time for the entire cohort was 5.2 years; 4.6 years for patients in the 2001-2005 group compared with 6.1 years for the $2006-2010$ cohort $(\mathrm{P}=0.002)$. The improvement was primarily seen among patients $>65$ years; the 6 -year OS rate improving from $31-56 \%$; $\mathrm{P}<0.001$. Only $10 \%$ of patients died during the 1 st year in the latter group, compared with $17 \%$ in the earlier cohort $(\mathrm{P}<0.01)$, suggesting improvement in early mortality (3). Chimeric antigen receptors (CARs) are artificial fusion proteins that incorporate an antigen-recognition domain and T-cell signaling domains. CAR-T cells (CAR-Ts) represent a promising novel approach for treating patients with MM, since they may be able to kill MM cells that are resistant to standard therapies. MM antigens, including CD138, CD38, signaling lymphocyte-activating molecule 7 and $\kappa$ light chain, are under investigation as CAR targets. Although CAR-T therapies for $\mathrm{MM}$ are currently at an early stage of development, they may improve treatment of patients with MM (4).

Exosomes are extracellular lipids bilayer vesicles of $30-100 \mathrm{~nm}$ in diameter that contain a variety of proteins and nucleic acid components. Their density range is $1.13-1.19 \mathrm{~g} / \mathrm{ml}$ in sucrose density gradient solution (5). Exosomes are present in almost all body fluids, including plasma, saliva, milk, 
cerebrospinal fluid, urine and semen, and are also present in the tumor microenvironment (6). It has been reported that exosomes from tumor cells mediate cell communication in the tumor microenvironment (7). A previous study demonstrated that tumor-derived exosomes (TEXs) tend to exert immune suppression and can block the differentiation of bone marrow progenitor cells into dendritic cells (DCs) (8). Furthermore, exosomes can carry transforming growth factor $\beta 1$ (TGF- $\beta 1$ ) and change the response of $\mathrm{T}$ cells to interleukin 2 (IL-2), allowing the transformation of lymphocytes into regulatory $\mathrm{T}$ cells (Tregs) rather than cytotoxic $\mathrm{T}$ cells (9). In addition, TEXs promote the activation and accumulation of Treg cells (10). Similarly, TEX stimulate the production of prostaglandin E2, IL- 6 and TGF- $\beta$ by myeloid-derived suppressor cells, resulting in the formation of a strong immunosuppressive environment in tumor lesions (11-13). Previous studies reported that $\mathrm{MM}$-derived exosomes might be involved in the differentiation and functional regulation of osteoclasts, promotion of angiogenesis and immune suppression $(14,15)$. However, the effects of MM-derived exosomes on the quantity and function of $\mathrm{T}$ cells remain unknown.

Tregs have a crucial role in resolving inflammation and achieving tissue homeostasis following infection through multiple mechanisms, including the production of the inhibitory cytokines IL-10 and TGF- $\beta$, the regulation of nutrient and cytokine availability, and the inhibition of DCs and macrophages maturation and function (16). Perforin, granzyme B (GrB) and Fas ligand (FasL) are cytotoxic molecules used by CD8+ T lymphocytes and natural killer cells to induce apoptosis of target cells (tumor or infected cells) (17). In the present study, IL-10 and TGF- $\beta$ were selected to evaluate the function of Tregs, whereas perforin and GrB were selected to evaluate the function of CD8+ T cells, in order to evaluate the effect of myeloma derived exosomes on the function of $\mathrm{T}$ lymphocytes, and to understand the possible mechanism of the effect of myeloma cells on $\mathrm{T}$ lymphocytes.

\section{Materials and methods}

Patients. Peripheral blood from patients newly diagnosed with MM and 45 adult HDs were collected to evaluate the potential effect of MM cell-derived exosomes on CD4+ T, CD8+ T and Treg cell function. The present study included 45 patients with MM (19 women and 26 men; age range, 44-85 years; median age, 68 years) who were treated at the Department of Hematology of Tianjin Medical University General Hospital (Tianjin, China) from June 2016 to December 2017. All HDs and patients with MM provided written consent prior to the study. This study was performed according to the Declaration of Helsinki and was approved by the Ethics Committee of Tianjin Medical University General Hospital.

Magnetic-activated cell sorting (MACS). Peripheral blood $(5 \mathrm{ml})$ was collected from HDs and patients with MM into EDTA-coated tubes. Peripheral blood mononuclear cells (PBMCs) were isolated by Ficoll-Paque density gradient centrifugation. The diluted blood was slowly added to the equal volume Ficoll-Hypaque solution, and then centrifuged at $860 \mathrm{x} \mathrm{g}$ for $20 \mathrm{~min}$ at $4^{\circ} \mathrm{C}$. The mononuclear lymphocyte cell layer was transferred to another centrifuge tube using a sterile pipet (this will appear as a white, cloudy band between the plasma and the Ficoll-Hypaque layers). Cells were washed three times with sterile PBS (the volume of the mononuclear cell layer) and centrifuged at $450 \mathrm{x}$ g for $10 \mathrm{~min}$ at $20^{\circ} \mathrm{C}$. The supernatant was discarded and the mononuclear lymphocyte cells were resuspended in sterile PBS for cell counting. Every $10^{7}$ PBMCs were re-suspended in $80 \mu 1$ PBS. Subsequently, CD4+, CD8+ and Treg cells (CD4+CD25+CD127 dim) were isolated from PBMCs by using human CD4, CD8 and Treg cell MACS kits (cat. nos. 130-095-248, 130-098-194 and 130-094-775, respectively; all from BD Biosciences), according to the manufacturer's instructions. The purity of the cell populations obtained was evaluated using a CytoFLEX flow cytometer (Beckman Coulter, Inc.) (Fig. S1).

Exosome isolation. Firstly, fetal bovine serum (FBS; HyClone; GE Healthcare Life Sciences) was placed into polyallomer centrifuge tubes (Beckman Coulter, Inc.) and ultracentrifuged (Beckman Coulter, Inc.) for exosome depletion. After ultracentrifugation at $100,000 \mathrm{x}$ for $18 \mathrm{~h}$ at $4^{\circ} \mathrm{C}$, exosomes from $\mathrm{FBS}$ were at the bottom of the centrifugal tubes. The supernatant collected as exosome-free serum was filtered using a $0.22-\mu \mathrm{m}$ aseptic filter (EMD Millipore) and subsequently used for cell culture (18). The OPM2 and U266B1 cell lines purchased from the Cell Center of Chinese Academy of Sciences and cultured for $48 \mathrm{~h}$ in RPMI-1640 medium (Gibco; Thermo Fisher Scientific, Inc.) containing $10 \%$ exosome-free serum and placed at $37^{\circ} \mathrm{C}$ in a humidified incubator containing $5 \% \mathrm{CO}_{2}$. The conditioned medium was then collected and centrifuged at $250 \mathrm{x} \mathrm{g}$ for $10 \mathrm{~min}$ at $25^{\circ} \mathrm{C}$, and the cell-free supernatant was obtained for exosome separation. The supernatant was divided into several sterile centrifuge tubes (cat. no. 430791; Corning, Inc.) and centrifuged at $4^{\circ} \mathrm{C}$ and $2,000 \mathrm{x}$ g for $30 \mathrm{~min}$ to remove cells and debris. The supernatant was carefully collected and filtered using a $0.22-\mu \mathrm{m}$ aseptic filter for sterilization. This filtered cell-free conditioned medium was transferred to the Pierce protein concentrator (cat. no. 88532S; Thermo Fisher Scientific, Inc.) and centrifuged at $4,000 \mathrm{x}$ g for $30 \mathrm{~min}$ at $4^{\circ} \mathrm{C}$ to concentrate the medium and remove soluble protein $(<150 \mathrm{KDa})$ and small particles $(<15 \mathrm{~nm})(19)$. The concentrated medium was subsequently incubated with Total Exosome Isolation reagent (Invitrogen; Thermo Fisher Scientific, Inc.) (volume ratio of supernatant to reagent was $2: 1$ ) at $4^{\circ} \mathrm{C}$ overnight and centrifuged at $10,000 \mathrm{xg}$ for $1 \mathrm{~h}$ at $4^{\circ} \mathrm{C}$. The pellet at the bottom of the centrifuge tube represented the exosomes, which were resuspended in PBS or serum-free medium for further co-culturing with T lymphocytes. The ultracentrifugation method was also used to obtain exosomes (18) and to compare them with the exosomes obtained from the aforementioned method, under transmission electron microscopy.

Transmission electron microscopy (TEM). The thin formvar/carbon film coated 200 mesh copper EM grids (cat. no. G200H-Cu; Electron Microscopy Sciences) were used for exosomes loading. Purified exosomes were fixed with $1 \mathrm{ml}$ of $2 \%$ paraformaldehyde for $5 \mathrm{~min}$ at room temperature. Exosome suspension $(5-7 \mu \mathrm{l})$ solution was added to the grids and incubated for $2 \mathrm{~min}$ at room temperature, and the exosome-loading grids were subsequently stained with $\sim 20$ drops of filtered 3\% phosphotungstic acid solution for 
3 min at room temperature. The grids were rinsed with distilled water to remove the excess staining solution and left to dry at room temperature for $10 \mathrm{~min}$. The exosomes were observed under a TEM (HT7700; Hitachi, Ltd.) at $80 \mathrm{kV}(\mathrm{x} 20 \sim 40 \mathrm{~K})$ (Fig. 1A-D) (20).

Cell culture with exosomes. CD4+ T, CD8+ T or Treg cells isolated from HDs and patients with MM were co-cultured with exosomes (100 $\mu \mathrm{g} / 10^{5}$ cells) isolated from OPM-2 and U266B1 cells, and cultured in RPMI-1640 medium with $10 \%$ FBS free of exosomes for $48 \mathrm{~h}$ at $37^{\circ} \mathrm{C}$ in a humidified incubator containing $5 \% \mathrm{CO}_{2}$. Cell apoptosis, cell viability and expression of certain proteins were next evaluated. CD4+ T cells from 15 HDs were co-cultured with two different concentrations (50 and $100 \mu \mathrm{g} / 10^{5}$ cells) of exosomes from OPM2 cells. The control group was treated with sterile PBS. The early apoptotic rate of CD4+ T cells cultured with a low and high concentration of exosomes was $11.92 \pm 2.59$ and $13.42 \pm 3.13 \%$, respectively. The early apoptotic rate of $\mathrm{CD} 4+\mathrm{T}$ cells in the control group was $9.41 \pm 3.00 \%$. These results demonstrated that the early apoptotic rate of CD4+ T cells significantly increased in the high exosome concentration group (100 $\mu \mathrm{g} / 10^{5}$ cells) compared with the control group (Fig. 2A-C). Thus, this exosome concentration $\left(100 \mu \mathrm{g} / 10^{5}\right.$ cells $)$ was selected for co-culture of CD4+ T, CD8+ T and Treg cells.

Western blotting. Exosomes, OPM2 and U266B1 cells were lysed using RIPA buffer (Thermo Fisher Scientific, Inc.) on ice for $30 \mathrm{~min}$. Protein quantification was performed using the Pierce BCA Protein Analysis kit (Thermo Fisher Scientific, Inc.), according to the manufacturers' instructions. Protein lysates from exosomes, OPM2 and U266B1 cells were boiled at $100^{\circ} \mathrm{C}$ for $5 \mathrm{~min}$. Equal amount of protein $(30 \mu \mathrm{g})$ was loaded and separated by $10 \%$ SDS-PAGE for $30 \mathrm{~min}$ and transferred onto a nitrocellulose $(0.45 \mu \mathrm{m})$ membrane for $110 \mathrm{~min}$ (Bio-Rad Laboratories, Inc.). Membranes were blocked with $5 \%$ non-fat skimmed milk for $1 \mathrm{~h}$ at room temperature and incubated with monoclonal antibodies against CD63, which is a specific (although not the only one) marker of exosomes (18) (1:1,000; cat. no. ab59479; Abcam) and heat shot protein 70 (HSP70; 1:1,000; cat. no. 4872; Cell Signaling Technology, Inc.) at $4^{\circ} \mathrm{C}$ overnight. The HRP-conjugated goat anti-Rabbit IgG (1:10,000; cat. no. 7074S; Cell Signaling Technology, Inc.) was added as secondary antibody for $1 \mathrm{~h}$ at room temperature. Membranes were washed three times with TBS containing Tween-20 (0.05\%), and bands were detected using an enhanced chemiluminescence substrate (GE Healthcare Bio-Sciences).

Flow cytometry. For the cell apoptosis assay, $1 \times 10^{5} \mathrm{CD} 4+$ $\mathrm{T}, \mathrm{CD} 8+\mathrm{T}$ or Treg cells were seeded in a 24 -well plate and co-cultured with exosomes $\left(100 \mu \mathrm{g} / 10^{5}\right.$ cells) for $48 \mathrm{~h}$. Apoptosis was evaluated by staining the cells with FITC Annexin V Apoptosis Detection kit (cat. no. 556547; BD Biosciences), according to the manufacturer's instructions using a CytoFLEX flow cytometer (Beckman Coulter, Inc.). Unlabeled cells were used as controls.

The gating strategy of flow cytometry was performed as follows: First, unstained cells were detected, cells were displayed on the forward scatter (FSC)-side scatter (SSC) scatter plot and the target cell population was circled by gates.
Then, the two-parameter logFL1 (FL1, flow1, FITC)-logFL2 (FL2, flow2, PE) was established and the cells within gates in the scatter plots were analyzed. It was ensured that $>98 \%$ of cells were located in the center of the lower left quadrant and that this region was negative. Secondly, only Annexin V-FITC-labeled cells were detected and FL1-FL2 scatter plots were checked to ensure that there were no particles in the upper left and right quadrants. Appearance of particles in the upper quadrant was indicative of fluorescence leakage, which was adjusted by increasing the compensation of FL1 leakage to FL2 fluorescence. If this regulation did not effectively remove the positive signal of FL2, the voltage of FL2 was lowered. Using this method, cells labeled only with propidium iodide (PI) were detected and compensation was adjusted if necessary. Thirdly, Annexin V and PI-labeled cells were analyzed by flow cytometry. The right lower and upper quadrants were considered as early and late apoptotic cells, respectively, and the sum corresponded to the apoptotic rate (Fig. S2).

$\mathrm{CD} 8+\mathrm{T}$ cells were permeabilized using BD Cytofix/Cytoperm ${ }^{\mathrm{TM}}$ reagent (BD Biosciences), and added $5 \mu$ l perforin-PE (cat. no. 130-096-578; Miltenyi) or Granzyme B-PE (cat. no. 130-101-351; Miltenyi), incubated at room temperature for $15 \mathrm{~min}$ in the dark, and then washed with PBS for flow cytometric detection of intracellular expression of perforin and Granzyme B. Isoform-matched isotypes were used as controls for extra and intracellular staining. Cells were immediately analyzed using Beckman CytoFLEX flow cytometer and CytExpert software (version 2.1; Beckman Coulter, Inc.). Quantification of $\mathrm{GrB}$ and perforin was performed according to the percentage of positive cells.

Cell viability. The sorted CD4+ T, CD8+ T and Treg cells were seeded into 96 well plates $\left(2 \times 10^{4}\right.$ cells $/ 100 \mu \mathrm{l}$ per well $)$, and co-cultured with OPM2/U266-exosomes $\left(100 \mu \mathrm{g} / 10^{5}\right.$ cells, $10 \mu \mathrm{l} /$ well) or PBS (10 $\mu \mathrm{l} /$ well as control) for $48 \mathrm{~h}$ at $37^{\circ} \mathrm{C}$. After cell incubation, $10 \mu \mathrm{l} \mathrm{CCK-8} \mathrm{(cat.} \mathrm{no.} \mathrm{EC020;} \mathrm{Engreen}$ Biosystem Co. Ltd.) reagent was added to the wells and incubated for $4 \mathrm{~h}$ at $37^{\circ} \mathrm{C}$ in a humidified incubator containing $5 \%$ $\mathrm{CO}_{2}$. Cell viability was analyzed at a wavelength of $450 \mathrm{~nm}$, using a microplate reader (GEN5; BioTek Instruments, Inc.).

ELISA. Following Treg cell $\left(1 \times 10^{5}\right.$ cells $/ 500 \mu \mathrm{l}$ per well into a 24 well plate) incubation with exosomes ( $100 \mu \mathrm{g} / 10^{5}$ cells) for $48 \mathrm{~h}$ at $37^{\circ} \mathrm{C}$, the cell culture was collected and centrifuged at $710 \mathrm{x} \mathrm{g}$ for $10 \mathrm{~min}$ at room temperature. The supernatant was separated to assess IL-10 and TGF- $\beta$ [Hangzhou MultiSciences (Lianke) Biotech, Co., Ltd.] concentration according to the manufacturer's instructions with a colorimetric reader (GEN5; BioTek Instruments, Inc.). The minimum detectable cytokine levels for IL-10 and TGF- $\beta$ were 0.59 and $3.36 \mathrm{pg} / \mathrm{ml}$, respectively.

Statistical analysis. The results were analyzed with GraphPad Prism 6.0 software (GraphPad Software, Inc.) and SPSS 20.0 software (SPSS Inc.). Data are expressed as the mean \pm standard error of the mean. ANOVA of randomized block design was used for comparison of apoptosis rate and viability of HD/MM-CD4+ T, CD8+ T and Treg cells, level of perforin, Granzyme B, IL-10 and TGF- $\beta$ among the three groups (OPM2 exosome, U266B1 exosome and control groups), with 
A

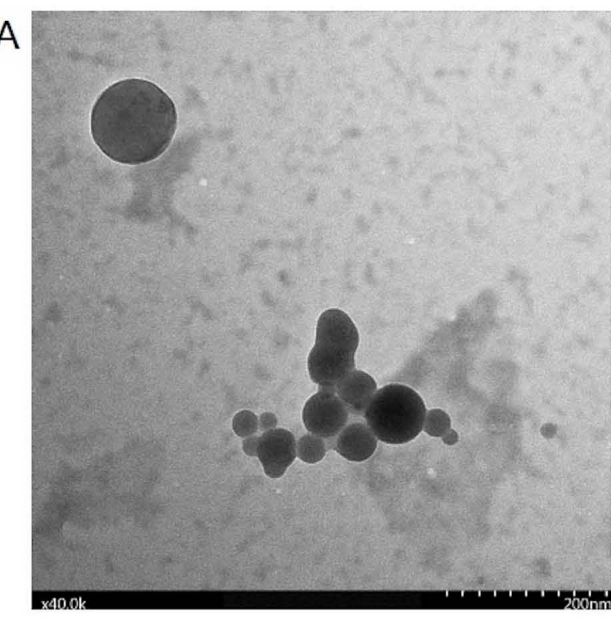

C

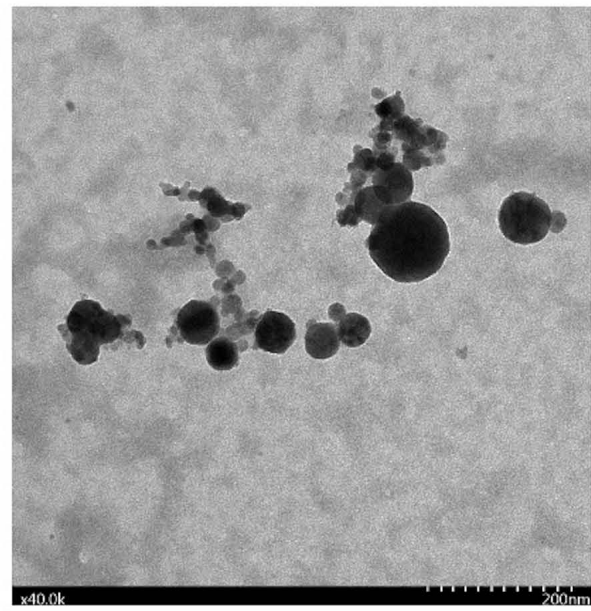

E

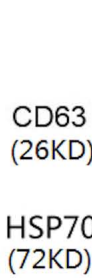

Exo Cell Lys

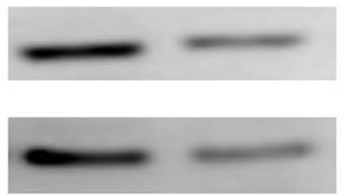

B

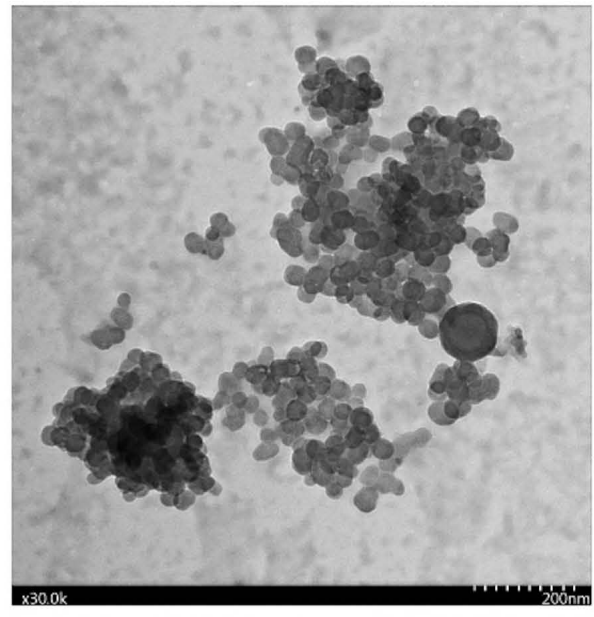

D

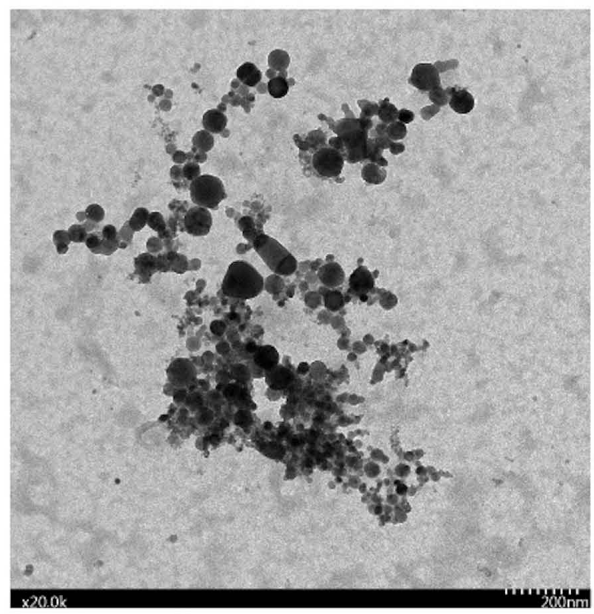

U266B1
Exo Cell Lys

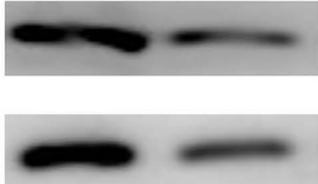

Figure 1. Exosomes observed by transmission electron microscopy. (A) Exosomes isolated by ultracentrifugation had intact continuous membranes and a diameter of 30-150 nm (magnification, $40.0 \mathrm{k}$ ). (B) Exosomes isolated by ultracentrifugation in clusters (magnification, $30.0 \mathrm{k}$ ). (C) Exosomes isolated using the Total Exosome Isolation reagent kit had intact continuous membranes and a diameter of 30-150 nm (magnification, 40.0 k). (D) Exosomes isolated using the Total Exosome Isolation reagent kit in clusters (magnification, $20.0 \mathrm{k}$ ). (E) Western blotting analysis of CD63 and HSP70 protein expression in exosomes from the OPM2 and U226B1 cells lines and cell lysates of OPM2 and U226B1 cells. HSP70, HSP 70, heat shot protein 70; Exo, exosome; Lys, lysate.

Dunnett's post hoc test. Interpolation to the standard curve of the measurements was obtained through linear regression using GraphPad Prism software version 6 (GraphPad Software, Inc.) (21). All experiments were performed in triplicate. $\mathrm{P}<0.05$ was considered to indicate a statistically significant difference.

\section{Results}

Effect of MM cell-derived exosomes on CD4+ T lymphocytes. The results from the TEM analysis demonstrated that MM cell-derived exosomes had intact continuous membranes and a diameter of 30-150 nm (Fig. 1). The central area was darker with a circled bright area around it, which is a typical morphological characteristic of exosomes $(22,23)$. The exosomes separated from conditioned medium of the OPM 2 cell line by ultracentrifugation were uniform in size. Fig. 1A demonstrates that the exosomes isolated by ultracentrifugation had intact continuous membranes and a diameter of 30-150 nm. Fig. 1B presents exosomes isolated by ultracentrifugation in clusters. The exosomes isolated using the Total Exosome Isolation reagent kit were similar in morphology to the exosomes isolated by ultracentrifugation. The diameter of exosomes isolated using the Total Exosome Isolation reagent kit was $30-150 \mathrm{~nm}$, as presented in Fig. 1C. A large number of clustered exosomes isolated using the Total Exosome Isolation reagent 
kit is presented in Fig. 1D. The results from western blotting demonstrated that exosomes extracted from the two MM cell lines were positive for CD63 and HSP70 staining, which are specific markers of exosomes. In addition, CD63 and HSP70 protein expression in the exosomes of the OPM2 and U266B1 cell lines was higher compared with that of OPM2 and U266B1 cell lysates (Fig. 1E). The TEM results demonstrated that the exosomes extracted using the Exosome Isolation reagent kit were similar in morphology to the exosomes extracted via ultracentrifugation.

CD4+ T cells from 15 HDs were co-cultured with two different concentrations (50 and $100 \mu \mathrm{g} / 10^{5}$ cells) of exosomes from OPM2 cells. The control group was treated with sterile PBS. The early apoptotic rate of CD4+ T cells cultured with a low and high concentration of exosomes was $11.92 \pm 2.59$ and $13.42 \pm 3.13 \%$, respectively. The early apoptotic rate of CD4+ T cells in the control group was $9.41 \pm 3.00 \%$. These results demonstrated that the early apoptotic rate of CD4+ T cells significantly increased in the high exosome concentration group $\left(100 \mu \mathrm{g} / 10^{5}\right.$ cells) compared with the control group (Fig. 2A-C). Thus, this exosome concentration $\left(100 \mu \mathrm{g} / 10^{5}\right.$ cells) was selected for co-culture of CD4+ T, CD8+ T and Treg cells.

CD4+ T cells from 15 HDs and 15 patients with MM were collected and co-cultured with exosomes from the OPM2 or U266B1 cell lines for $48 \mathrm{~h}$. The apoptotic rate of HD-CD4+ T cells in the OPM2 (6.24 $\pm 1.24 \%)$ and U266B1 $(5.42 \pm 1.07 \%)$ groups was higher than that in the control group $(4.37 \pm 0.96 \%)$. The result of comparing these three groups revealed a statistically significant difference $(\mathrm{P}=0.004)$. The apoptotic rate of HD-CD4+ T cells in OMP2 group was significantly higher than the control group $(\mathrm{P}=0.002)$ (Fig. 2D-G). The cell viability of HD-CD4+ T cells in the OPM2 $(95.34 \pm 4.58 \%)$ and U266B1 $(85.45 \pm 6.09 \%)$ groups was decreased compared with that of the control group (100\%), which was statistically significant $(\mathrm{P}=0.024)$. The viability of $\mathrm{CD} 4+\mathrm{T}$ cells in the $\mathrm{U} 266 \mathrm{~B} 1$ group was inhibited $(\mathrm{P}=0.015$; Fig. $2 \mathrm{H})$. The apoptotic rate of MM-CD4+ T cells in the OPM2 $(14.56 \pm 4.65 \%)$ and U266B1 $(16.42 \pm 5.08 \%)$ groups was increased compared with that of the control group $(13.83 \pm 5.69 \%)$, although this was not significant ( $\mathrm{P}>0.05$; Fig. 2I). In addition, the viability of MM-CD4+ T cells in the OPM2 group (98.61 $\pm 2.80 \%)$, U266B1 group $(100.02 \pm 5.48 \%)$ and the control group (100\%) showed no statistical significance $(\mathrm{P}>0.05$; Fig. $2 \mathrm{~J})$.

Effect of MM cell-derived exosomes on CD8+ T lymphocytes. CD8+ T cells from 15 HDs and 15 patients with MM were co-cultured with exosomes from OPM2 or U266B1 cells for $48 \mathrm{~h}$. The apoptotic rate of HD-CD8+ T cells in the OPM2 $(9.97 \pm 1.28 \%)$ and U266B1 $(11.00 \pm 1.75 \%)$ groups was significantly lower than that in the control group $(16.12 \pm 2.95 \%$; both $\mathrm{P}<0.001$; Fig. 3A-C and G). The viability of HD-CD8+ T cells in the OPM2 $(112.63 \pm 3.88 \%)$ and U266B1 $(111.70 \pm 3.62 \%)$ groups was significantly increased compared with that of the control group ( $\mathrm{P}=0.030$ and 0.045 , respectively; Fig. $3 \mathrm{H})$. The apoptotic rate of MM-CD8+ $\mathrm{T}$ cells in the OPM2 $(14.40 \pm 4.86 \%)$ and U266B1 $(14.39 \pm 4.36 \%)$ groups showed no statistically significant difference $(17.37 \pm 4.05 \%$; $\mathrm{P}>0.05$; Fig. 3D-F presents the apoptotic rates of MM-CD8+ T cells in the control, OPM2 and U266B1 groups, respectively. Fig. 3I demonstrates the statistical analysis of the apoptotic rates of MM-CD8+ T cells among the three groups). The viability of MM-CD8+ T cells in the OPM2 $(101.58 \pm 10.82 \%)$ and U266B1 (100.31 $\pm 10.08 \%)$ groups was not different from the cell viability in the control group ( $\mathrm{P}>0.05$; Fig. $3 \mathrm{~J})$.

CD8+ T cells from 15 HDs and 15 patients with MM were co-cultured with exosomes from OPM2 or U266B1 cells for $48 \mathrm{~h}$. In addition to the 15 healthy donors, 15 patients with myeloma were also randomly selected for assessment. The expression of perforin and GrB after cell permeabilization was assessed by flow cytometry. The level of perforin in HD-CD8+ T cells was lower in the OPM2 $(10.82 \pm 2.53 \%)$ and U266B1 $(9.34 \pm 2.36 \%)$ groups compared with that in the control group $(12.76 \pm 3.31 \%)(\mathrm{P}=0.038)$. The level of perforin in HD-CD8+ T cells in the U266B1 group was inhibited, showing statistical significance $(\mathrm{P}=0.024)$, but the level of perforin showed no statistical significance between the OPM2 group and the control group ( $\mathrm{P}>0.05$; Fig. 4A-C present the perforin levels of HD-CD8+ T cells in the control, OPM2 and U266B1 groups, respectively. Fig. 4G demonstrates the statistical analysis of perforin levels of HD-CD8+ T cells among the three groups). The results demonstrated that U266B1-derived exosomes had a more significant effect on the perforin secretion of HD-CD8+ T cells. The level of GrB in HD-CD8+ T cells in the OPM2 $(31.87 \pm 6.10 \%)$ and U266B1 $(32.99 \pm 7.08 \%)$ groups was not significantly different from that of the control group $(28.74 \pm 6.21 \%$; P>0.05; Fig. 4D-F showed scatter diagram of level of $\mathrm{GrB})$. The level of perforin in MM-CD8+ $\mathrm{T}$ cells in the OPM2 $(6.48 \pm 1.06 \%)$ and U266B1 $(5.63 \pm 1.15 \%)$ groups was significantly lower than that in the control group $(10.55 \pm 2.50 \% ; \mathrm{P}=0.008)$. The difference between the perforin level in the OPM2 and U266B1 groups was statistically significant $(\mathrm{P}=0.017$ and $\mathrm{P}=0.006$, respectively; Fig. $4 \mathrm{H})$. There was no statistical significance in the level of GrB in MM-CD8+ T in OPM2 group $(34.48 \% \pm 9.98 \%)$, U266B1 group $(41.49 \pm 9.17 \%)$ and the control group $(34.91 \pm 8.14 \%)(\mathrm{P}>0.05)$.

Effect of MM cell-derived exosomes on Tregs. Treg cells from 15 HDs and 15 patients with MM were co-cultured with exosomes from OPM2 or U266B1 cells for $48 \mathrm{~h}$. The apoptotic rate of HD-Treg cells in OPM2 group $(15.33 \pm 3.87 \%)$ and U266 group $(11.71 \pm 2.71 \%)$ was lower than that in the control group $(19.61 \pm 3.50 \%)$. The apoptotic rate of HD-Treg cells in U266 group was significantly lower than that of the control group $(\mathrm{P}=0.003$; Fig. 5A-C present the apoptotic rates of HD-Treg cells in the control, OPM2 and U266B1 groups, respectively; Fig. 5G demonstrated the statistical analysis of apoptotic rates of HD-Treg among the three groups). The viability of HD-Treg cells in the OPM2 group (139.54 \pm 23.24$)$ and U266B1 group $(173.48 \pm 34.99 \%)$ was higher than the control group $(100 \%)$. But the viability of HD-Treg cells only in U266B1 group was significantly higher than the control group ( $\mathrm{P}=0.037$; Fig. $5 \mathrm{H})$. The apoptotic rate of MM-Treg cells in the U266B1 group $(37.29 \pm 6.54 \%)$ was significantly increased compared with that of the control group $(29.95 \pm 6.68 \% ; \mathrm{P}=0.011)$. However, there was no significant difference between the apoptotic rate of MM-Treg cells in the OPM2 group $(30.91 \pm 7.25 \%)$ and the control group $(\mathrm{P}>0.05$; Fig. 5D-F present the apoptotic rates of MM-Treg cells in the control, OPM2 and U266B1 groups, respectively; Fig. 5I demonstrates the statistical analysis of 

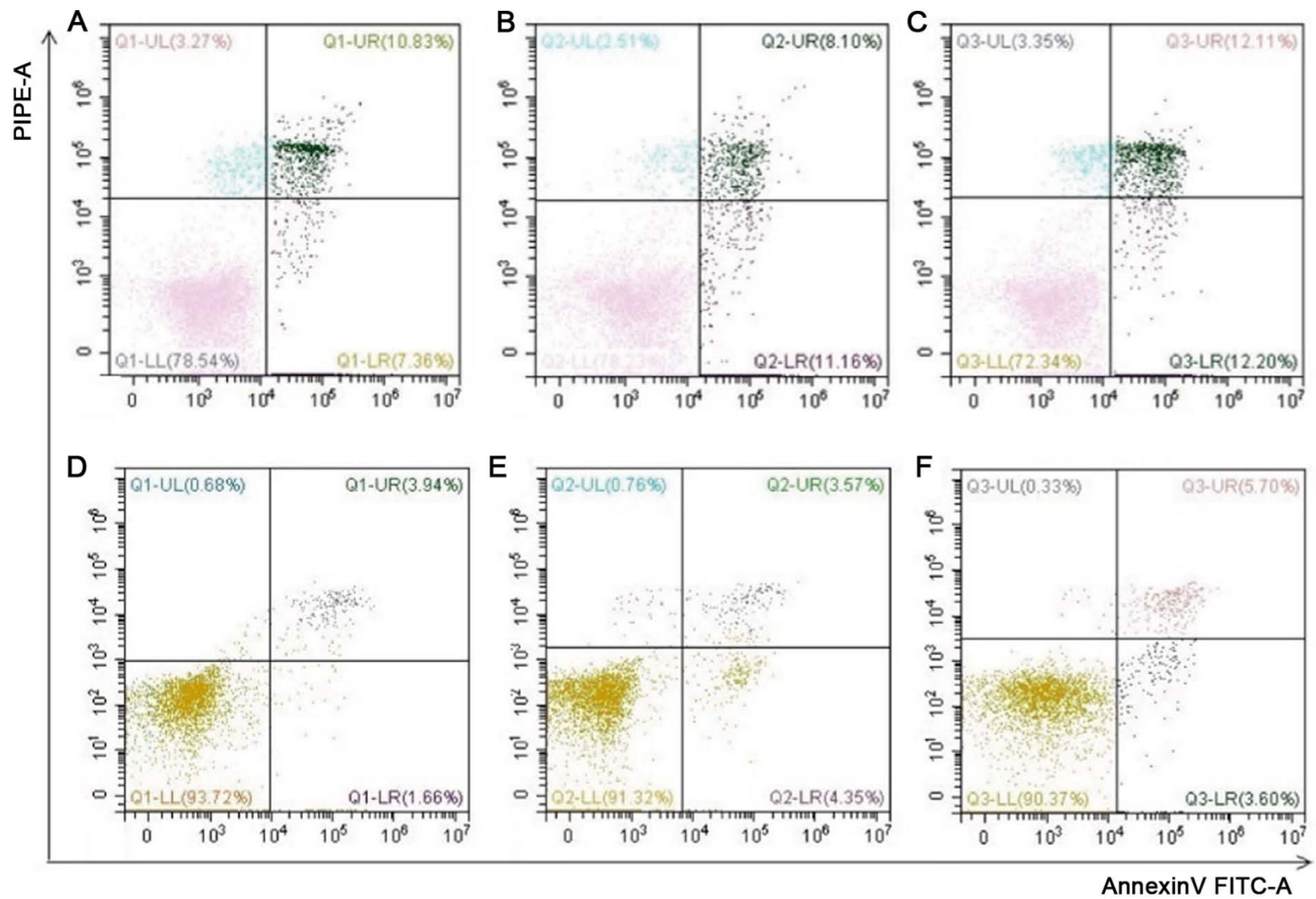

G

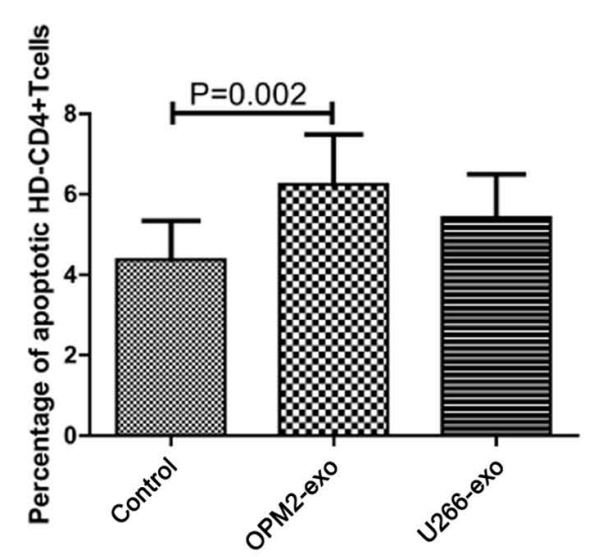

I

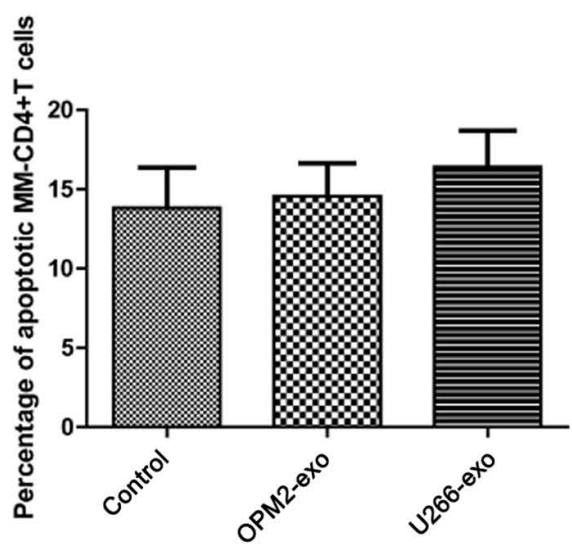

$\mathrm{H}$

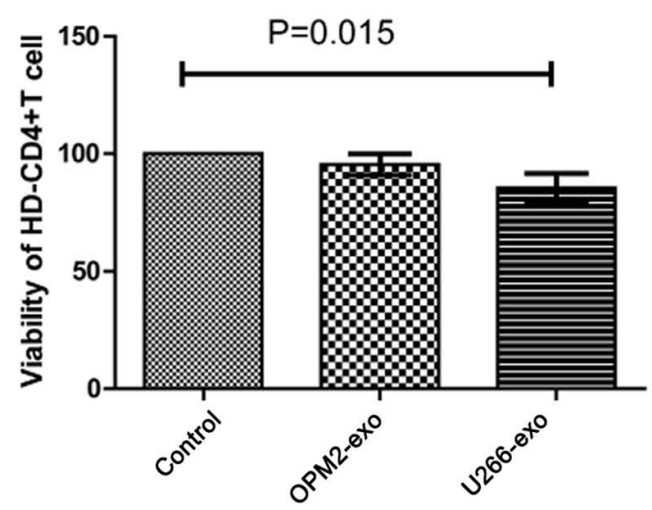

$\mathrm{J}$

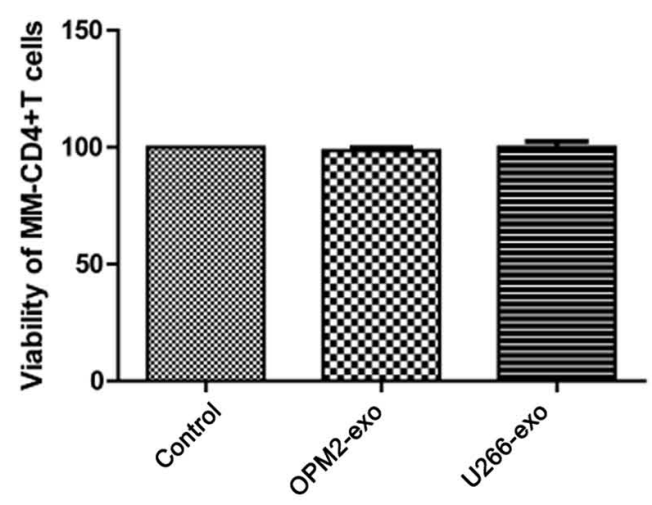

Figure 2. Effect of MM cell-derived exosomes on CD4+ T lymphocytes. (A) Apoptotic rate of HD-CD4+ T cells co-cultured without exosome (control). (B) Apoptotic rate of HD-CD4+ T cells co-cultured with OPM2-isolated exosomes (50 $\mu \mathrm{g} / 10^{5}$ cells). (C) Apoptotic rate of HD-CD4+ T cells co-cultured with OPM2-isolated exosomes (100 $\mu \mathrm{g} / 10^{5}$ cells). (D) Apoptotic rate of HD-CD4+ T cells co-cultured without exosome (control). (E) Apoptotic rate of HD-CD4+ T cells co-cultured with OPM2-derived exosomes. (F) Apoptotic rate of HD-CD4+ T cells co-cultured with U266B1-derived exosomes. (G) The apoptotic rate of HD-CD4+ T cells was significantly increased in the OPM2-derived exosomes. $(\mathrm{H})$ The viability of HD-CD4+ T cells was decreased in the U266B1-derived exosomes compared with that of the control $(\mathrm{n}=15)$. (I) The apoptotic rate of MM-CD4+T cells showed no statistical significance among the three groups $(n=15)$. (J) The viability of MM-CD4+ T cells showed no statistical significance among the three groups $(n=15)$. HD, healthy donor; MM, multiple myeloma; UL, upper left; UR, upper right; LL, lower left; LR, lower right; exo, exosome; FITC, fluorescein isothiocyanate; PI, propidium iodide; PE, phycoerythrin. 

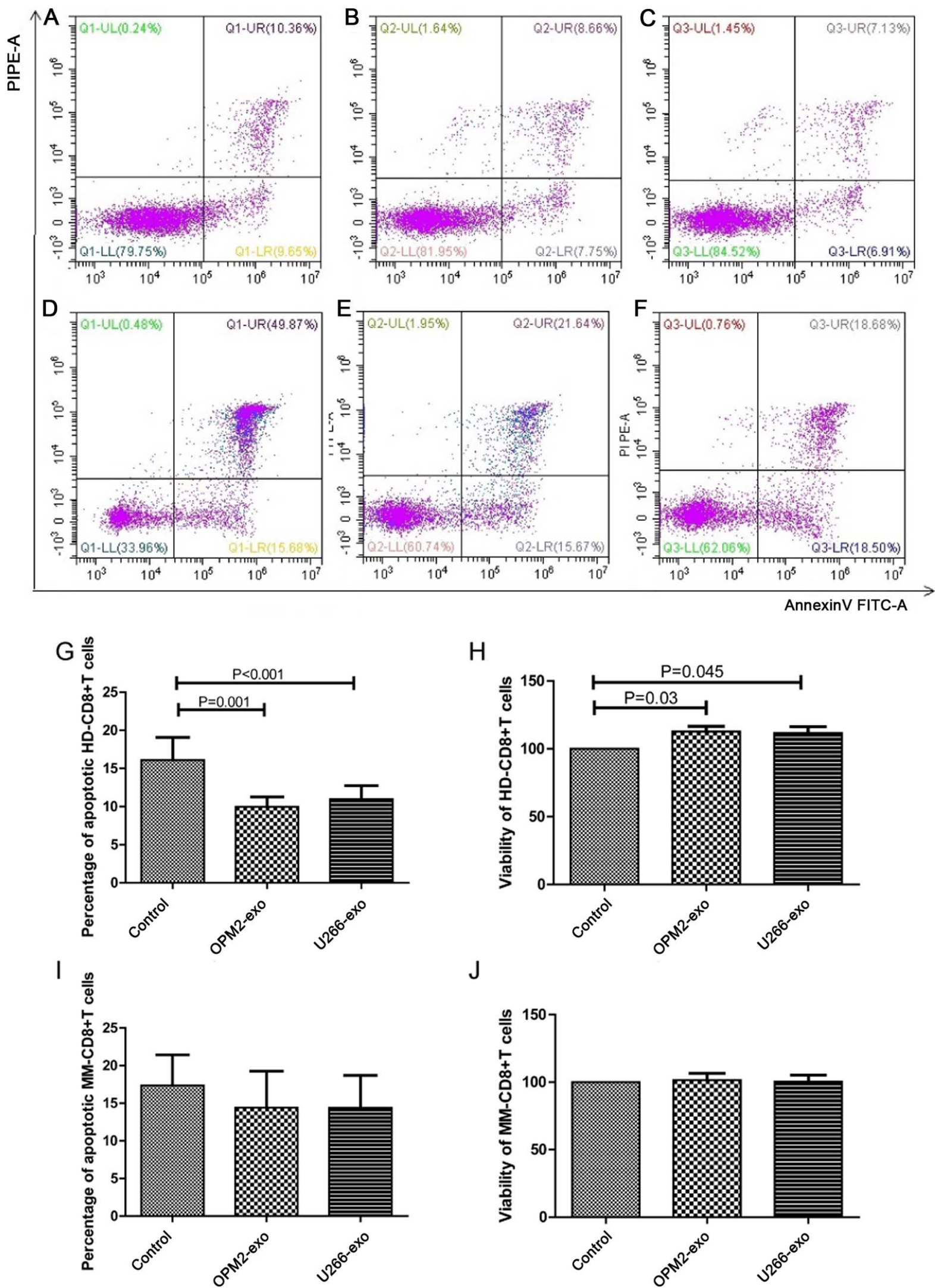

Figure 3. Effect of MM cell-derived exosomes on CD8+ T lymphocytes. Assessment of apoptosis by flow cytometry of HD-CD8+ T cells co-cultured with (A) Apoptotic rate of HD-CD8+ T cells co-cultured without exosome (control). (B) Apoptotic rate of HD-CD8+ T cells co-cultured with OPM2-derived exosomes. (C) Apoptotic rate of HD-CD8+ T cells co-cultured with U266B1-derived exosomes. (D) Apoptotic rate of MM-CD8+ T cells co-cultured without exosome (control). (E) Apoptotic rate of MM-CD8+ T cells co-cultured with OPM2-derived exosomes. (F) Apoptotic rate of MM-CD8+ T cells co-cultured with U266B1-derived exosomes. (G) The apoptotic rate of HD-CD8+ T cells co-cultured with OPM2- and U266B1-derived exosomes was significantly decreased compared with the control group $(\mathrm{n}=15)$. (H) The viability of HD-CD8+ T cells co-cultured with OPM2- and U266B1-derived exosomes was significantly increased compared with the control group $(\mathrm{n}=15)$. (I) The apoptotic rate of MM-CD8+T cells showed no statistical significance among the three groups $(\mathrm{n}=15)$. (J) The viability of MM-CD8+ T cells showed no statistical significance among the three groups $(\mathrm{n}=15)$. HD, healthy donor; MM, multiple myeloma; UL, upper left; UR, upper right; LL, lower left; LR, lower right; exo, exosome; FITC, fluorescein isothiocyanate; PI, propidium iodide; PE, phycoerythrin. 
A

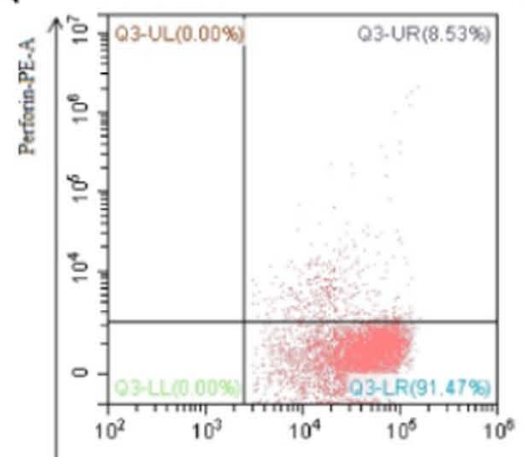

B

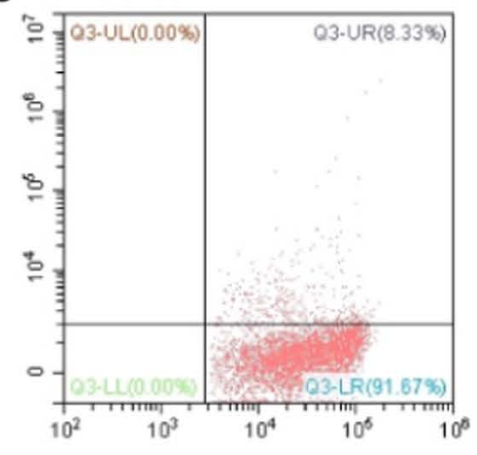

C

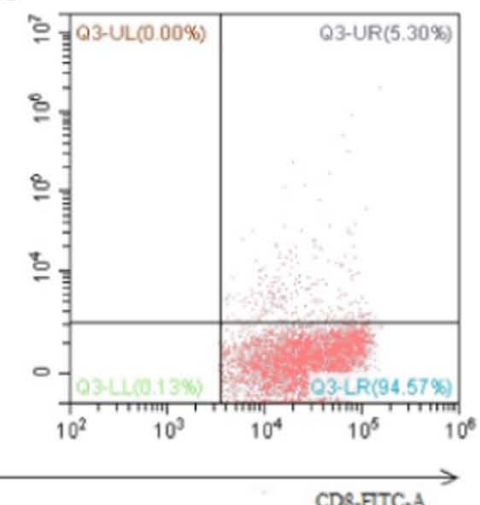

D

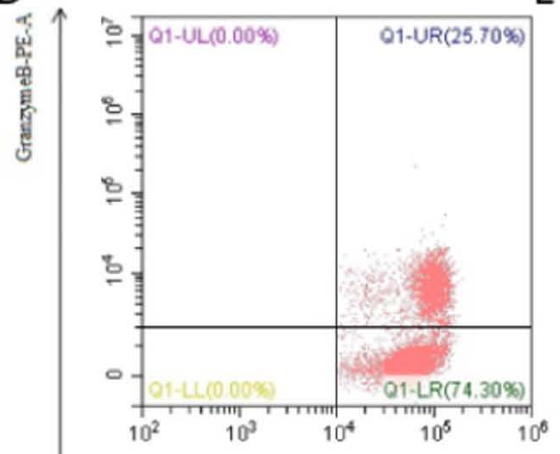

E

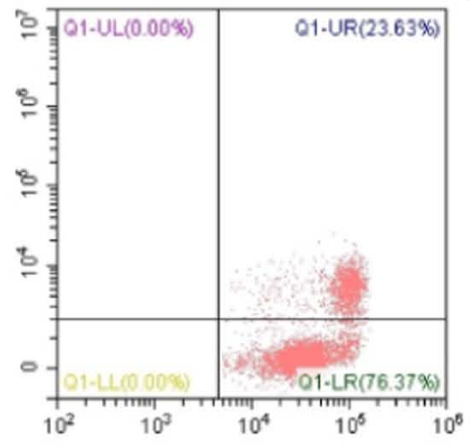

$\mathrm{F}$

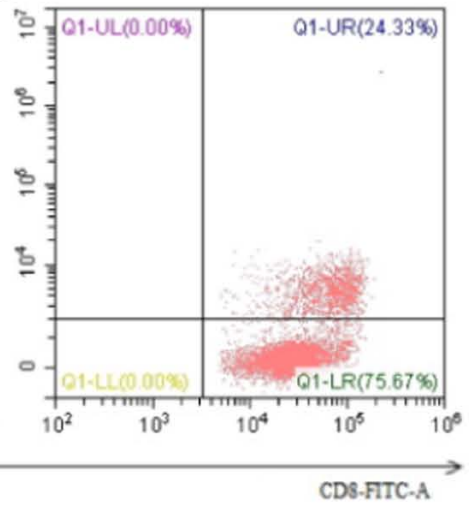

$\mathrm{G}$

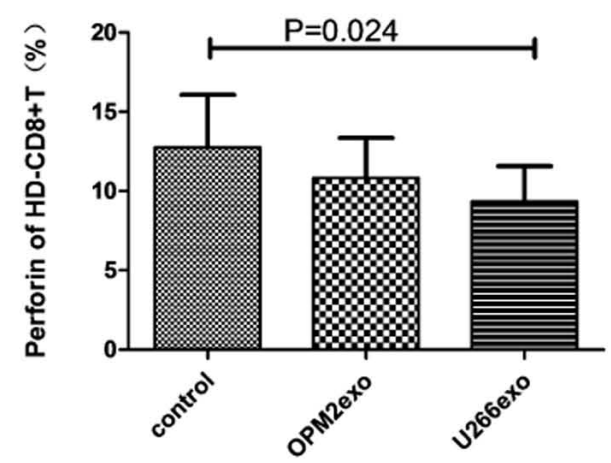

I

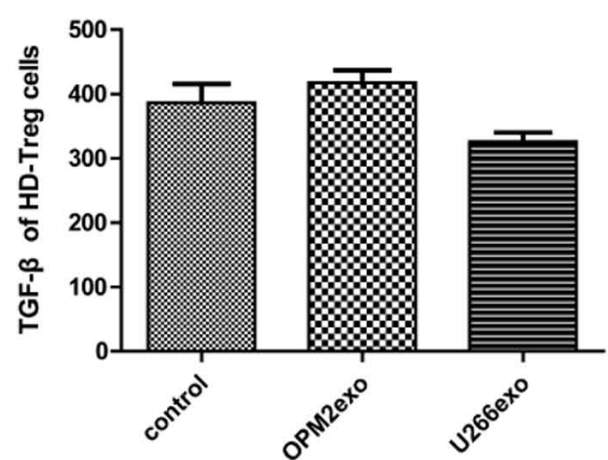

$\mathrm{H}$

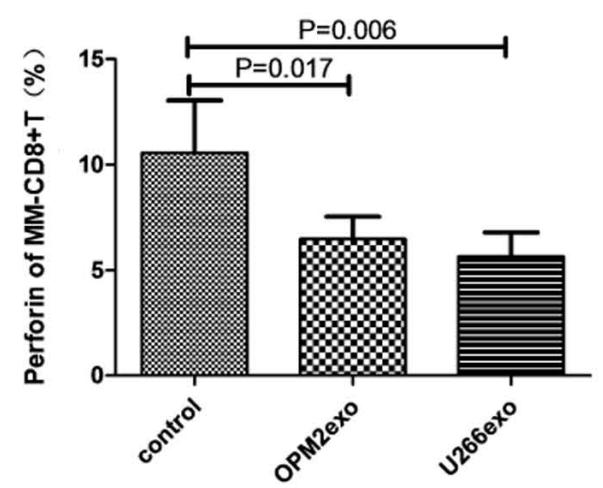

$J$

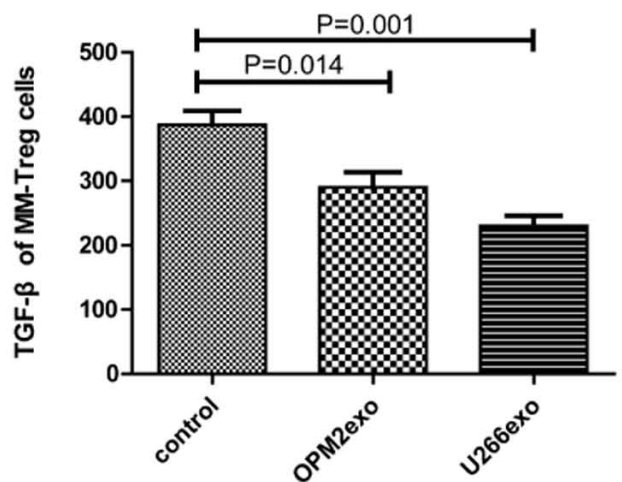

Figure 4. Effect of MM cell-derived exosomes on the function of CD8 and Treg cells. (A) Perforin levels of HD-CD8+ T cells co-cultured without exosome (control). (B) Perforin levels of HD-CD8+ T cells co-cultured with OPM2-derived exosomes. (C) Perforin levels of HD-CD8+ T cells co-cultured with U266B1-derived exosomes. (D) Granzyme B levels of HD-CD8+ T cells co-cultured without exosome (control). (E) Granzyme B levels of HD-CD8+ T cells co-cultured with OPM2-derived exosomes. (F) Granzyme B levels of HD-CD8+ T cells co-cultured with U266B1-derived exosomes. (G) The levels of perforin secreted by HD-CD8+ T cells was decreased in the U266B1-derived exosome group compared with the control group. (H) The levels of perforin secreted by MM-CD8+T cells was significantly decreased both in the OPM2 and U266B1-derived exosome groups compared with the control group. (I) The levels of TGF- $\beta$ in the supernatant of HD-Treg cells showed no statistical significance and (J) the levels of TGF- $\beta$ secreted by MM-Tregs was decreased in the OPM2 and U266B1-derived exosome groups compared with that of the control $(n=15)$. HD, healthy donor; IL, interleukin; MM, multiple myeloma; TGF- $\beta$, transforming growth factor $\beta$; UL, upper left; UR, upper right; LL, lower left; LR, lower right; exo, exosome; FITC, fluorescein isothiocyanate; PE, phycoerythrin. 

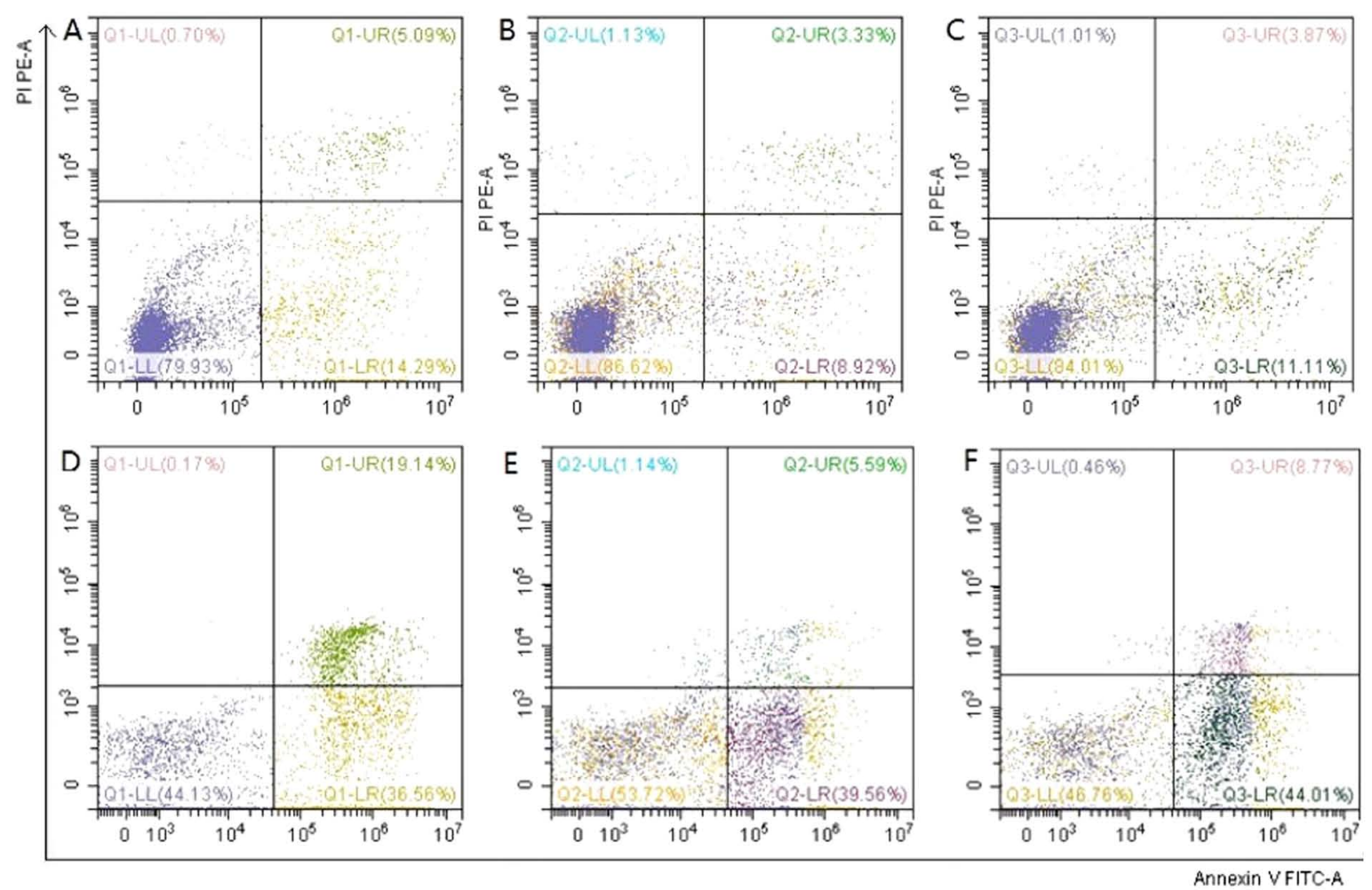
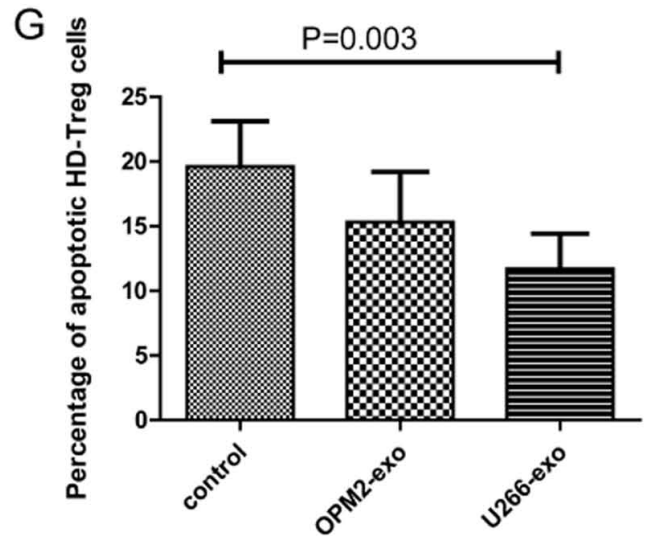

I

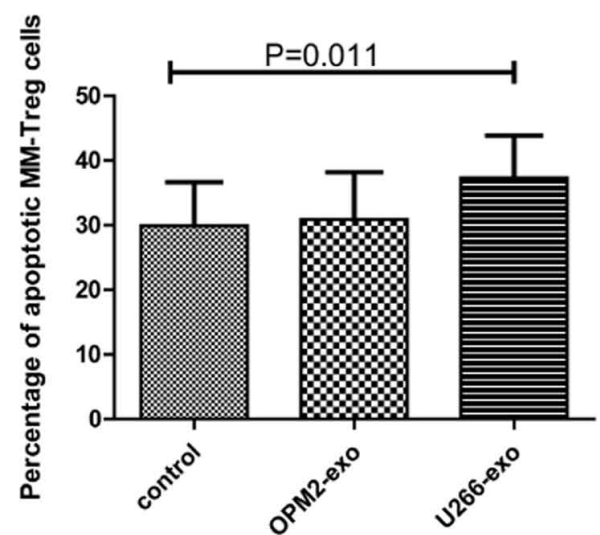

$\mathrm{H}$

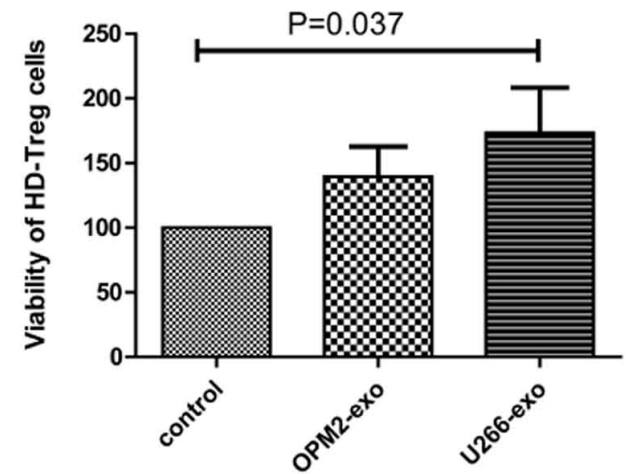

$J$

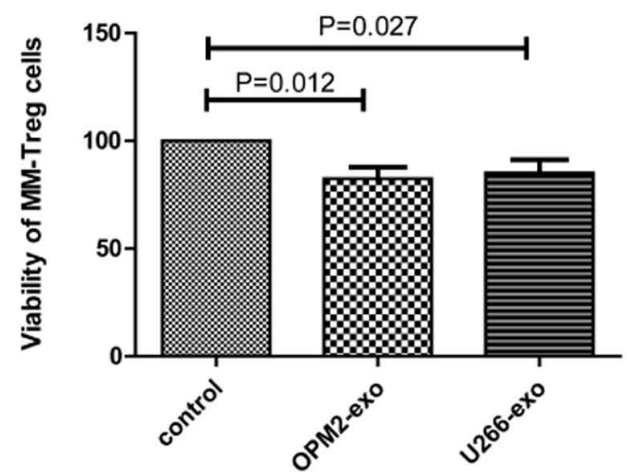

Figure 5. Effect of MM cell-derived exosomes on Tregs. (A) Apoptotic rate of HD-Treg cells co-cultured without exosome (control). (B) Apoptotic rate of HD-Treg cells co-cultured with OPM2-derived exosomes. (C) Apoptotic rate of HD-Treg cells co-cultured with U266B1-derived exosomes. (D) Apoptotic rate of MM-Treg cells co-cultured without exosome (control). (E) Apoptotic rate of MM-Treg cells co-cultured with OPM2-derived exosomes. (F) Apoptotic rate of MM-Treg cells co-cultured with U266B1-derived exosomes. (G) The apoptotic rate of HD-Tregs was significantly decreased in the U266B1-derived exosome group compared with that of the control. (H) The viability of HD-Tregs was significantly increased in the U266B1-derived exosome group. (I) The apoptotic rate of MM-Tregs was significantly increased in the U266B1-derived exosome group compared with that of the control. (J) The viability of MM-Tregs was decreased in the OPM2- and U266B1-derived exosome groups $(\mathrm{n}=15)$. HD, healthy donor; MM, multiple myeloma; Treg, regulatory T cell; UL, upper left; UR, upper right; LL, lower left; LR, lower right; exo, exosome; FITC, Fluorescein isothiocyanate; PI, Propidium iodide; PE, Phycoerythrin. 
apoptotic rates of MM-Treg among the three groups). The

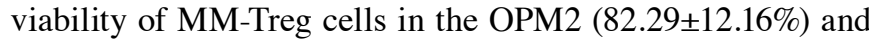
U266B1 $(85.09 \pm 13.50 \%)$ groups was decreased compared with that of the control group $(\mathrm{P}=0.013)$. The viability of MM-Treg cells in the OPM2 group and U266B1 group was significantly lower compared with that of the control group $(\mathrm{P}=0.012$ and $\mathrm{P}=0.027$, respectively; Fig. 5J).

Treg cells from 15 HDs and 15 patients with MM were co-cultured with exosomes from OPM2 or U266B1 cells for $48 \mathrm{~h}$, and the IL-10 and TGF- $\beta$ levels in the supernatant were detected by ELISA. The level of IL-10 in the supernatant of HD-Treg cells in the OPM2 $(18.53 \pm 8.08 \mathrm{pg} / \mathrm{ml})$ and U266B1 $(13.51 \pm 7.83 \mathrm{pg} / \mathrm{ml})$ groups was increased compared with the control group $(8.49 \pm 4.02 \mathrm{pg} / \mathrm{ml})$. The difference in IL-10 levels between HD-Treg cells in the OPM2 and the control group was significant $(\mathrm{P}=0.043)$. There was no significant difference between the IL-10 level in the supernatant of HD-Treg cells in the OPM2 group and the IL-10 level in the supernatant of HD-Treg cells in the U266B1 group $(\mathrm{P}>0.05)$. The IL-10 level in the supernatant of MM-Treg cells in the OPM2 $(3.29 \pm 1.84 \mathrm{pg} / \mathrm{ml})$ and U266B1 $(2.60 \pm 1.72 \mathrm{pg} / \mathrm{ml})$ groups was increased compared with that of the control group $(1.39 \pm 1.02 \mathrm{pg} / \mathrm{ml})$, although this was not significant ( $\mathrm{P}>0.05)$.

The level of TGF- $\beta$ in the supernatant of HD-Treg cells in OPM2 (417.57 $\pm 19.33 \mathrm{pg} / \mathrm{ml}), \mathrm{U} 266 \mathrm{~B} 1(325.96 \pm 14.32 \mathrm{pg} / \mathrm{ml})$ and control group $(386.60 \pm 28.89 \mathrm{pg} / \mathrm{ml})$ were significantly different $(\mathrm{P}=0.033)$, but the difference between the OPM2, $\mathrm{U} 266 \mathrm{~B} 1$ and control groups was not significant $(\mathrm{P}>0.05$; Fig. $4 \mathrm{I})$. The level of TGF- $\beta$ in the supernatant of MM-Treg cells in the OPM2 (290.29 $\pm 23.21 \mathrm{pg} / \mathrm{ml}), \mathrm{U} 266 \mathrm{~B} 1(325.96 \pm 14.32 \mathrm{pg} / \mathrm{ml})$ and the control group $(387.49 \pm 21.60 \mathrm{pg} / \mathrm{ml})$ were statistically significant $(\mathrm{P}=0.001)$. The level of TGF- $\beta$ in the supernatant of MM-Treg cells in the OPM2 and U266B1 group were significantly lower than the control group $(\mathrm{P}=0.014$ and $\mathrm{P}=0.001$, respectively; Fig. 4J).

\section{Discussion}

A new evolutionarily conserved system of intercellular communication used by single-cell and multicellular organisms has been identified. This system involves information transfer between cells via extracellular vesicles (EVs). Mammalian cells spontaneously release EVs of various sizes $(30-5,000 \mathrm{~nm})$ into all body fluids. The current EV nomenclature is based on size and markers present on membranes. It comprises small EVs or exosomes (30-150 $\mathrm{nm}$ in diameter), intermediate-sized EVs or microvesicles (200-1,000 $\mathrm{nm}$ in diameter) and apoptotic bodies (1,000-5,000 $\mathrm{nm}$ in diameter) (24). In the present study, and according to the scale on the images (Fig. 1), the vesicles isolated were $30-150 \mathrm{~nm}$ in diameter, suggesting that they were exosomes. The results from western blotting demonstrated the presence of CD63 and HSP70, confirming that these EVs were exosomes.

Suppression of antitumor immune responses by tumor-derived soluble factors, including inhibitory cytokines, has long been recognized as a mechanism contributing to tumor progression (25). Although the existence of cross-talk between tumor and recipient immune cells is widely accepted (5-7), the underlying mechanisms remain unclear.
The present study investigated the effect of MM cell-derived exosomes on the apoptosis, viability, and function of $\mathrm{T}$ cells from HDs and patients with MM. The results demonstrated the immune-suppression effect of TEX on T cells and the abnormal immune function of T cells in patients with MM.

In the present study, MM-derived exosomes promoted the apoptosis and inhibited the viability of CD4+ T cells in HDs. These findings had been previously described. Furthermore, Ludwig et al (26) reported that exosomes of patients with active disease (AD) were significantly more effective than exosomes of patients with no evident disease (NED) in inducing apoptosis of CD8+ $\mathrm{T}$ cells, suppression of CD4+ T cell proliferation and upregulation of regulatory $\mathrm{T}$ cell (Treg) suppressor functions.

In the present study, MM-derived exosomes promoted proliferation, inhibited apoptosis and decreased perforin expression in CD8+ T cells from HDs. These results suggested that, although the quantity of CD8+ T cells increased, their function decreased, which further confirmed the inhibitory effect of exosomes on CD8+ T cells from HDs. The ability of TEXs to induce CD8+ T cell apoptosis is due to the presence of the membrane-associated form of FasL and major histocompatibility complex (MHC) class I molecules on TEXs $(27,28)$. TEXs with the highest content of FasL and MHC class I molecules can most actively induce $\mathrm{T}$ cell apoptosis, which can be partially blocked by anti-Fas or anti-MHC class I antibodies, and completely blocked in the presence of both antibodies (27). Although the role of FasL carried by TEXs in the apoptosis induction of activated Fas+ CD8+ T cells has been described, the role of MHC class I molecules remains unclear. In the peripheral blood of patients with cancer, almost all CD8+ lymphocytes express CD95 at their surface (29), and a number of them express programmed cell death 1 (PD-1) (30). Because TEXs in the serum of these patients carry FasL and/or programmed cell death-ligand 1 (PD-L1), the corresponding death pathways (Fas/FasL or PD-1/PD-L1, respectively) may be responsible for the spontaneous apoptosis of CD8+ T cells observed in vivo (31).

The present study did not evaluate the secretion of cytokines from CD4+ T cells, including interferon $\gamma($ IFN- $\gamma$ ) and IL-4. Ye et al (32) had studied the effect of TEXs on cytokines secreted by CD4+ T cells and reported that, under exosome stimulation, the secretion of IL-1 $\beta$, IL- 6 and IL-10 from CD4+ T cells is increased, which is not the case for IL-4. However, only IL-6 increased secretion is significant. In addition, the secretion of tumor necrosis factor $\alpha$ (TNF $\alpha)$, IL-12, granulocyte-macrophage colony-stimulating factor, INF- $\gamma$, IL-2 and IL-17 from CD4+ T cells under TEXs stimulation is decreased; however, only the secretion of IL-12, IL-17, IL-2 and IFN- $\gamma$ is significantly decreased. Since CD4+ T cells can be subdivided into different cell subsets, including Th1/Th2, Treg and CD17+ T, the present study focused on Treg of CD4+ T cells, and only IL-10 and TGF- $\beta$ secretion was evaluated.

MM-derived exosomes inhibited the apoptosis and promoted the proliferation of Treg cells from HDs. It was reported that plasma exosomes from patients with nasopharyngeal carcinoma could partially enhance the immune-suppression function of normal Treg cells (33). In addition, TEXs could promote the generation and function of Tregs. When co-incubated with exosomes purified from 
supernatants of tumor cells, CD4+CD25- T cells are converted into Tregs, which display elevated expression of IL-10, TGF- $\beta$ and CTLA4 (33). Muller et al (13) co-cultured T lymphocytes with TEXs or dendritic cells-derived exosomes (DEXs) and detected the expression level of immune response-associated genes. The results demonstrated that, in activated T cells, TEXs and DEXs increase the mRNA expression of numerous genes, and that Tregs are more sensitive to the effect of co-culture with TEXs and DEXs than CD4+ T and CD8+ T subsets. Furthermore, in Tregs co-cultured with TEXs or DEXs, the CD39 gene, which regulates the adenosine pathway, is overexpressed, leading to increased production of adenosine. TEX also induces the upregulation of CD69 in CD4+ T, resulting in the loss of function of CD4+ T cells (13).

The effect of TEXs on Tregs is different from their effect on CD4+ T cells. The change of 23 immune response-associated mRNA expression level in activated Tregs is higher than that in other $\mathrm{T}$ cells, suggesting that activated Tregs may be more sensitive to TEX-mediated effects than other T cells. After incubated with TEXs, CD4+ T cells were activated, and the gene profiles demonstrated that the expression of immunosuppressive genes, including cyclooxygenase-2 (COX-2), cytotoxic T-lymphocyte-associated protein 4 , Fas, FasL and TGF- $\beta$, was decreased compared with before incubation, which was associated with the decrease in mean of intensity fluorescence (MIF) of CD69 on the cell surface. TEXs may therefore inhibit the activation of $\mathrm{CD} 4+\mathrm{T}$ cells by promoting the translation of inhibitory proteins. TEXs can upregulate the expression of immunosuppressive genes in activated Tregs and promote their rapid transformation into inhibitory proteins, including TGF- $\beta$, IL-10, COX-2, CD39, CD73 and adenosine (13). These findings suggest that TEXs could mediate the differential regulation of CD4+ T and Treg gene expression and cell function, and confirm the results from the present study demonstrating that MM-derived exosomes promoted the apoptosis and inhibited the proliferation of CD4+ T cells from HDs, and inhibited the apoptosis and promoted the proliferation and IL-10 expression of Tregs from HDs.

The ratio of CD4+/CD8+ T cells in the blood of patients with MM decreased compared with healthy donors (34). A previous study reported Treg cells measured by FOXP3 expression are significantly decreased in the blood of patients with monoclonal gammopathy of undetermined significance (MGUS) and MM compared with healthy donors, despite their elevated number of CD25+/CD4+ cells (35). This group suggested that CD25+ T cells from patients with MGUS or MM fail to inhibit the proliferation of PBMCs treated with anti-CD3, suggesting that MM Tregs are dysfunctional. However, the results remain conflicting, and Treg frequency is alternatively described as increased $(36-38)$ or decreased $(35,39)$ in patients with MM. Notably, patients with higher percentage of Treg in peripheral blood have a decreased overall survival (median overall survival 21 months vs. not reached, $\mathrm{P}=0.013$ ) (38).

Since TEXs contain tumor antigens, they may be used as vaccines for immunotherapy of cancer $(31,40,41)$. For example, exosomes released from MM cells that are designed to express $\mathrm{TNF}-\alpha\left(\mathrm{EXO}_{\mathrm{TNF}-\alpha}\right)$ can induce a more efficient tumor antigen-specific CD8+ $\mathrm{T}$ cell response and inhibit tumor growth than exosomes designed to express IL-2 $\left(\mathrm{EXO}_{\mathrm{IL}-2}\right)$ or INF- $\gamma\left(\mathrm{EXO}_{\mathrm{INF}-\gamma}\right)$ in mice (42).
Although the role of MM-derived exosomes on $\mathrm{T}$ cell immunity is not comprehensive, evidence is accumulating to demonstrate that MM-derived exosomes are involved in the immune abnormalities of Treg cells and the formation of bone marrow immunosuppressive microenvironment. Therefore, further studies are required to clarify the regulatory mechanism of exosomes on Treg, so as to provide theoretical basis for alleviating the immunosuppression of bone marrow microenvironment and improving the prognosis of patients with MM.

\section{Acknowledgements}

Not applicable.

\section{Funding}

The present study was supported by the Tianjin Key Projects of Health and Family Planning Commission (grant no. 15KG150) and the Anticancer Major Special Project of Tianjin (grant no. 12ZCDZSY18000).

\section{Availability of data and materials}

All data generated or analyzed during the present study are included in this published article.

\section{Authors' contributions}

RF designed the present study. QS and LD performed most of the experiments, analyzed the data, drew the figures and drafted the initial manuscript. JC, FJ and SY helped with ELISA, western blotting and the flow cytometry. HL and ZL analysed and interpreted the data, and RF checked the manuscript and figures. All authors read and approved the final version of the manuscript.

\section{Ethics approval and consent to participate}

The present study was approved by the Ethics Committee of Tianjin Medical University General Hospital (Tianjin, China; approval no. IRB2020-WZ-064). All healthy donors and patients with multiple myeloma provided written informed consent prior to the study.

\section{Patient consent for publication}

Written informed consent was obtained from the patients for the publication of this report and any accompanying images.

\section{Competing interests}

The authors declare that they have no competing interests.

\section{References}

1. Rajkumar SV, Dimopoulos MA, Palumbo A, Blade J, Merlini G, Mateos MV, Kumar S, Hillengass J, Kastritis E, Richardson P, et al: International Myeloma Working Group updated criteria for the diagnosis of multiple myeloma. Lancet Oncol 15: e538-e548, 2014.

2. Ferlay J, Steliarova-Foucher E, Lortet-Tieulent J, Rosso S, Coebergh JW, Comber H, Forman D and Bray F: Cancer incidence and mortality patterns in Europe: Estimates for 40 countries in 2012. Eur J Cancer 49: 1374-1403, 2013. 
3. Kumar SK, Dispenzieri A, Lacy MQ, Gertz MA, Buadi FK, Pandey S, Kapoor P, Dingli D, Hayman SR, Leung N, et al: Continued improvement in survival in multiple myeloma: Changes in early mortality and outcomes in older patients. Leukemia 28: 1122-1128, 2014.

4. Mikkilineni L and Kochenderfer JN: Chimeric antigen receptor T-cell therapies for multiple myeloma. Blood 130: 2594-2602, 2017.

5. Zhang X, Yuan X, Shi H, Wu L, Qian H and Xu W: Exosomes in cancer: Small particle, big player. J Hematol Oncol 8: 83, 2015.

6. Yu S, Cao H, Shen B and Feng J: Tumor-derived exosomes in cancer progression and treatment failure. Oncotarget 6 : 37151-37168, 2015.

7. Milane L, Singh A, Mattheolabakis G, Suresh M and Amiji MM Exosome mediated communication within the tumor microenvironment. J Control Release 219: 278-294, 2015.

8. Yu S, Liu C, Su K, Wang J, Liu Y, Zhang L, Li C, Cong Y, Kimberly R, Grizzle WE, et al: Tumor exosomes inhibit differentiation of bone marrow dendritic cells. J Immunol 178 6867-6875, 2007.

9. Clayton A, Mitchell JP, Court J, Mason MD and Tabi Z: Human tumor-derived exosomes selectively impair lymphocyte responses to interleukin-2. Cancer Res 67: 7458-7466, 2007.

10. Szajnik M, Czystowska M, Szczepanski MJ, Mandapathil M and Whiteside TL: Tumor-derived microvesicles induce, expand and up-regulate biological activities of human regulatory $\mathrm{T}$ cells (Treg). PLoS One 5: e11469, 2010.

11. Chalmin F, Ladoire S, Mignot G, Vincent J, Bruchard M, Remy-Martin JP, Boireau W, Rouleau A, Simon B Lanneau D, et al: Membrane-associated Hsp72 from tumor-derived exosomes mediates STAT3-dependent immune suppressive function of mouse and human myeloid-derived suppressor cells. J Clin Invest 120: 457-471, 2010.

12. Xiang X, Poliakov A, Liu C, Liu Y, Deng ZB, Wang J, Cheng Z, Shah SV, Wang GJ, Zhang L, et al: Induction of myeloid-derived suppressor cells by tumor exosomes. Int J Cancer 124: 2621-2633, 2009.

13. Muller L, Mitsuhashi M, Simms P, Gooding WE and Whiteside TL: Tumor-derived exosomes regulate expression of immune function related genes in human T cell subsets. Sci Rep 6: 20254, 2016.

14. Wang J, De Veirman K, Faict S, Frassanito MA, Ribatti D, Vacca A and Menu E: Multiple myeloma exosomes establish a favourable bone marrow microenvironment with enhanced angiogenesis and immunosuppression. J Pathol 239: 162-173, 2016.

15. Raimondi L, De Luca A, Amodio N, Manno M, Raccosta S, Taverna S, Bellavia D, Naselli F, Fontana S, Schillaci O, et al: Involvement of multiple myeloma cell-derived exosomes in osteoclast differentiation. Oncotarget 6: 13772-13789, 2015.

16. Vignali DAA, Collison LW and Workman CJ: How regulatory T cells work. Nat Rev Immunol 8: 523-532, 2008.

17. Andersen MH, Schrama D, Thor Straten P and Becker JC: Cytotoxic T cells. J Invest Dermatol 126: 32-41, 2006.

18. Théry C, Amigorena S, Raposo G and Clayton A: Isolation and characterization of exosomes from cell culture supernatants and biological fluids. Curr Protoc Cell Biol Chapter 3: Unit 3.22, 2006.

19. Wang J, Hendrix A, Hernot S, Lemaire M, De Bruyne E, Van Valckenborgh E, Lahoutte T, De Wever O, Vanderkerken K and Menu E: Bone marrow stromal cell-derived exosomes as communicators in drug resistance in multiple myeloma cells. Blood 124: 555-566, 2014.

20. Jung MK and Mun JY: Sample preparation and imaging of exosomes by transmission electron microscopy. J Vis Exp 131: 56482, 2018

21. Quispe EÁ, Li XM and Yi H: Comparison and relationship of thyroid hormones, IL-6, IL-10 and albumin as mortality predictors in Case-mix critically ill patients. Cytokine 81: 94-100, 2016

22. Lobb RJ, Becker M, Wen SW, Wong CS, Wiegmans AP, Leimgruber A and Möller A: Optimized exosome isolation protocol for cell culture supernatant and human plasma. J Extracell Vesicles 4: 27031, 2015.

23. Vojtech L, Woo S, Hughes S, Levy C, Ballweber L, Sauteraud RP, Strobl J, Westerberg K, Gottardo R, Tewari M and Hladik F: Exosomes in human semen carry a distinctive repertoire of small non-coding RNAs with potential regulatory functions. Nucleic Acids Res 42: 7290-7304, 2014.
24. Boyiadzis $\mathbf{M}$ and Whiteside TL: The emerging roles of tumor-derived exosomes in hematological malignancies. Leukemia 31: 1259-1268, 2017.

25. Whiteside TL: Immune responses to malignancies. J Allergy Clin Immunol 125 (Suppl): S272-S283, 2010.

26. Ludwig S, Floros T, Theodoraki MN, Hong CS, Jackson EK, Lang S and Whiteside TL: Suppression of lymphocyte functions by plasma exosomes correlates with disease activity in patients with head and neck cancer. Clin Cancer Res 23: 4843-4854, 2017.

27. Kim JW, Wieckowski E, Taylor DD, Reichert TE, Watkins S and Whiteside TL: Fas ligand-positive membranous vesicles isolated from sera of patients with oral cancer induce apoptosis of activated T lymphocytes. Clin Cancer Res 11: 1010-1020, 2005.

28. Wieckowski EU, Visus C, Szajnik M, Szczepanski MJ, Storkus WJ and Whiteside TL: Tumor-derived microvesicles promote regulatory $\mathrm{T}$ cell expansion and induce apoptosis in tumor-reactive activated CD8+T lymphocytes. J Immunol 183: 3720-3730, 2009.

29. Kim JW, Tsukishiro T, Johnson JT and Whiteside TL: Expression of pro- and antiapoptotic proteins in circulating CD8+ T cells of patients with squamous cell carcinoma of the head and neck. Clin Cancer Res 10: 5101-5110, 2004.

30. Pardoll DM: The blockade of immune checkpoints in cancer immunotherapy. Nat Rev Cancer 12: 252-264, 2012.

31. Tran TH, Mattheolabakis G, Aldawsari H and Amiji M: Exosomes as nanocarriers for immunotherapy of cancer and inflammatory diseases. Clin Immunol 160: 46-58, 2015.

32. Ye SB, Li ZL, Luo DH, Huang BJ, Chen YS, Zhang XS, Cui J, Zeng YX and Li J: Tumor-derived exosomes promote tumor progression and T-cell dysfunction through the regulation of enriched exosomal microRNAs in human nasopharyngeal carcinoma. Oncotarget 5: 5439-5452, 2014.

33. Liu Y, Gu Y and Cao X: The exosomes in tumor immunity. Oncoimmunology 4: e1027472, 2015.

34. Mills KH and Cawley JC: Abnormal monoclonal antibody defined helper/suppressor T-cell subpopulations in multiple myeloma: Relationship to treatment and clinical stage. Br J Haematol 53: 271-275, 1983.

35. Prabhala RH, Neri P, Bae JE, Tassone P, Shammas MA, Allam CK, Daley JF, Chauhan D, Blanchard E, Thatte HS, et al: Dysfunctional T regulatory cells in multiple myeloma. Blood 107: 301-304, 2006.

36. Bryant C, Suen H, Brown R, Yang S, Favaloro J, Aklilu E, Gibson J, Ho PJ, Iland H, Fromm P, et al: Long-term survival in multiple myeloma is associated with a distinct immunological profile, which includes proliferative cytotoxic T-cell clones and a favourable Treg/Th17 balance. Blood Cancer J 3: e148, 2013.

37. Beyer M, Kochanek M, Giese T, Endl E, Weihrauch MR, Knolle PA, Classen S and Schultze JL: In vivo peripheral expansion of naive $\mathrm{CD} 4+\mathrm{CD} 25$ high FoxP3+ regulatory T cells in patients with multiple myeloma. Blood 107: 3940-3949, 2006

38. Giannopoulos K, Kaminska W, Hus I and Dmoszynska A: The frequency of T regulatory cells modulates the survival of multiple myeloma patients: Detailed characterisation of immune status in multiple myeloma. Br J Cancer 106: 546-552, 2012.

39. Feng P, Yan R, Dai X, Xie X, Wen H and Yang S: The alteration and clinical significance of Th1/Th2/Th17/Treg cells in patients with multiple myeloma. Inflammation 38: 705-709, 2015.

40. Andre F, Schartz NE, Chaput N, Flament C, Raposo G, Amigorena S, Angevin E and Zitvogel L: Tumor-derived exosomes: A new source of tumor rejection antigens. Vaccine 20 (Suppl 4): A28-A31, 2002

41. Natasha G, Gundogan B, Tan A, Farhatnia Y, Wu W, Rajadas J and Seifalian AM: Exosomes as immunotheranostic nanoparticles. Clin Ther 36: 820-829, 2014.

42. Xie Y, Bai O, Zhang $\mathrm{H}, \mathrm{Li} \mathrm{W}$ and Xiang J: Tumor necrosis factor gene-engineered J558 tumor cell-released exosomes stimulate tumor antigen P1A-specifc CD8 ${ }^{+} \mathrm{CTL}$ responses and antitumor immunity. Cancer Biother Radiopharm 25: 21-28, 2010.

This work is licensed under a Creative Commons Attribution-NonCommercial-NoDerivatives 4.0 International (CC BY-NC-ND 4.0) License. 